\title{
New Horizons in Understanding Appropriate Prehospital Identification and Trauma Triage for Older Adults
}

\author{
Abdullah Alshibani $\mathbb{D}^{1,2}$ \\ Jay Banerjee ${ }^{1,3}$ \\ Fiona Lecky $\mathbb{D D}^{4}$ \\ Timothy J Coats $\mathbb{D}^{3,5}$ \\ Meshal Alharbi $\mathbb{D}^{2,5}$ \\ Simon Conroy'
}

'Department of Health Sciences, College of Life Sciences, University of Leicester, Leicester, UK; ${ }^{2}$ Emergency Medical Services Department, College of Applied Medical Sciences, King Saud Bin Abdulaziz University for Health Sciences, Riyadh, Saudi Arabia; ${ }^{3}$ University Hospitals of Leicester NHS Trust, Leicester, UK;

${ }^{4}$ Centre for Urgent and Emergency Care Research, University of Sheffield, Sheffield, UK; ${ }^{5}$ Department of Cardiovascular Sciences, University of Leicester, Leicester, UK
Correspondence: Abdullah Alshibani Department of Health Sciences, College of Life Sciences, George Davies Centre, University of Leicester, 15 Lancaster Road, Leicester, LEI 7HA, UK

Email anaa3@le.ac.uk
This article was published in the following Dove Press journal: Open Access Emergency Medicine

\begin{abstract}
Caring for older people is an important part of prehospital practice, including appropriate triage and transportation decisions. However, prehospital triage criteria are designed to predominantly assess injury severity or high-energy mechanism which is not the case for older people who often have injuries compounded by multimorbidity and frailty. This has led to high rates of under-triage in this population. This narrative review aimed to assess aspects other than triage criteria to better understand and improve prehospital triage decisions for older trauma patients. This includes integrating frailty assessment in prehospital trauma triage, which was shown to predict adverse outcomes for older trauma patients. Furthermore, determining appropriate outcome measures and the benefits of Major Trauma Centers (MTCs) for older trauma patients should be considered in order to direct accurate and more beneficial prehospital trauma triage decisions. It is still not clear what are the appropriate outcome measures that should be applied when caring for older trauma patients. There is also no strong consensus about the benefits of MTC access for older trauma patients with regards to survival, in-hospital length of stay, discharge disposition, and complications. Moreover, looking into factors other than triage criteria such as distance to MTCs, patient or relative choice, training, unfamiliarity with protocols, and possible ageism, which were shown to impact prehospital triage decisions but their impact on outcomes has not been investigated yet, should be more actively assessed and investigated for this population. Therefore, this paper aimed to discuss the available evidence around frailty assessment in prehospital care, appropriate outcome measures for older trauma patients, the benefits of MTC access for older patients, and factors other than triage criteria that could adversely impact accurate prehospital triage decisions for older trauma patients. It also provided
\end{abstract} several suggestions for the future.

Keywords: undertriage, geriatrics, injury, emergency, paramedics, frailty

\section{Introduction}

The population of older adults has increased worldwide over the last years. More people in the world currently live into or beyond 60 years of age. ${ }^{1}$ The number of older adults aged 60 years and over has projected by $48 \%$ from 607 million in 2000

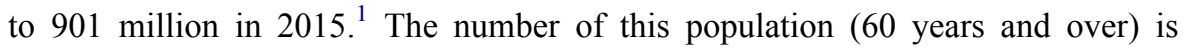
expected to reach a total of 2.1 billion by $2050 .{ }^{1}$ This means the rates of older adults requiring health care including trauma care will increase. Therefore, highquality trauma care for this population is needed including that of prehospital trauma care. 
Prehospital care represents an essential and important part of the patient's journey and plays a significant role in determining outcomes. One of the main principles of prehospital care is to get the right patient, to the right place, at the right time. ${ }^{2}$ This means prehospital assessment should accurately identify complaint(s), nature, and severity enabling appropriate triage decisions. This article aims to highlight and investigate the issues around prehospital trauma triage of older patients, discuss the current evidence, and provide recommendations for future improvement of prehospital care for older people.

\section{Scope of the Problem}

Many triage tools have been developed to aid prehospital care providers to make appropriate and accurate triage decisions for patients. However, this is far from true when it comes to the prehospital triage of people aged $\geq 55$ years, especially for trauma. The literature from the United States of America (USA) and Australia show increased rates of under-triage among this population. ${ }^{3-15}$ Under-triage is simply defined as the transportation of severely injured patients to lower-level Trauma Centers (TCs) or other Acute Care (AC) facilitates, as opposed to Major Trauma Centers (MTCs) (equivalent to major trauma service or Level I or II TCs). ${ }^{16}$ A number of recent studies in the USA developed trauma triage tools specific for older adults in order to improve early identification and appropriate triage and transportation decisions. ${ }^{8,12-14,17}$ Although most of these tools had better sensitivity than the current adult trauma triage tools, they had sub-optimal specificity. ${ }^{12-14}$ Only one recently developed triage tool has a better sensitivity with an acceptable reduction in the specificity when compared to current triage tool for adult trauma patients in predicting the need of MTC care (sensitivity: $93 \%$ vs $61 \%$, and specificity: $49 \%$ vs $61 \%$ ). ${ }^{8}$ Furthermore, the performance of this tool among older trauma patients is similar to the performance of the current triage tool in younger trauma patients (sensitivity: $93 \%$ vs $87 \%$, and specificity: $49 \%$ vs $44 \%$, respectively). ${ }^{8}$ However, using the cut-off point of $\geq 70$ years in this study represents a major limitation as a previous study from the USA has shown that the issue of under-triage can begin as early as the age of 50 years. ${ }^{4}$

Current triage tools predominantly assess injury severity or high-energy mechanism. However, older people usually have injuries compounded by multimorbidity and frailty. They also exhibit age-related anatomical and physiological changes, ${ }^{18-24}$ which could adversely affect the accuracy of the triage tool. This in turn risks inappropriate prehospital identification and transportation decisions. Therefore, applying traditional trauma triage criteria only, for the assessment of older adults, may not be effective. However, integrating additional assessment tools such as frailty assessment into prehospital trauma tirage may improve early identification of older patients who are at high risk of adverse outcomes.

Frailty assessment has been embedded in routine care for patients requiring emergency care in the United Kingdom (UK). Applying simple frailty assessment tools using, for example, the Clinical Frailty Scale (CFS) was shown recently to independently predict 30 -day mortality, inpatient delirium, and increased care level at discharge in trauma patients aged $\geq 65$ years. ${ }^{25}$ The application of the CFS in emergency care was determined to be feasible, reliable, and accurate. ${ }^{26}$ However, compliance to frailty attuned scores in prehospital care may impact their effectiveness in such setting as previous evidence showed that paramedics' compliance with trauma triage tools varied from a rate of $21 \%$ to $93 \%{ }^{27}$

Whilst there is reasonable evidence that care in MTCs benefits younger patients with severe injuries, it is uncertain whether or not the same benefits will accrue to injured older adults. This could be partially due to the lack of trauma-specific outcome measures for older people, ${ }^{28}$ thereby limiting the determination of benefits of MTC access. It also results from differences in aetiology whereby high energy transfer (road traffic collisions, sport, assault) is usually required to injure a young adult. However, from the seventh decade of life onwards, major injury is most likely to result from fall from a standing height. ${ }^{29}$ Older people are more likely to have low-level falls (ie, $<2$ meters) and when they occur, major injury is more likely to result compared to younger adults. ${ }^{29}$ The less robust injured structures may not respond to aggressive treatments (organ surgery and critical care) employed in MTCs. Hence, there is a need to clarify the optimal level of care that should be provided to older people to support Emergency Medical Service (EMS) personnel decision-making.

Little is known about factors other than triage criteria that could affect the triage decisions of older trauma patients including patient (or relative) choice, paramedics' training and familiarity with protocols, and their impact on outcomes.

The aim of this article is to provide an overview on prehospital frailty assessment, appropriate outcome 
measures for older trauma patients, the benefits of MTC access for older patients, and factors other than triage criteria that could impact accurate triage decisions for older trauma patients, discuss the evidence base surrounding these issues, and recommend possible solutions that require further scrutiny from prehospital care providers and policymakers within the healthcare system.

\section{Frailty Assessment in Prehospital Care}

Frailty is known to be an independent predictor of mortality, morbidity, and hospitalizations among older adults from studies including older trauma patients. ${ }^{30,31}$ The "frailty index" has been shown to be an independent predictor of poor health outcomes, in-hospital complications, and adverse discharge disposition among older trauma patients. $^{32-34}$ Hitherto, no frailty assessment tool has been used for older trauma patients as a method of prehospital triage.

With respect to applying frailty assessment in prehospital care, there is a limited evidence on the feasibility of assessing frailty and the validation of frailty assessment tools (Table 1). ${ }^{35-37}$ Two studies from Canada investigated the feasibility of the Care Partner - Comprehensive Geriatric Assessment (CP-CGA) and validity of the Care Partner-derived Frailty Index based upon Comprehensive Geriatric Assessment (CP-FI-CGA) to measure frailty in the prehospital phase by paramedics and in busy clinical practice (Table 1). ${ }^{35,36}$ One recent study from Australia assessed the perceptions of paramedic students about the application of the Edmonton Frail Scale (EFS) and the Groningen Frailty Index (GFI) for assessing and screening older adults in the prehospital phase (Table 1). ${ }^{37}$ Overall, frailty assessment and screening in the prehospital phase was recognised to be important and feasible.

Furthermore, two studies have investigated the application of clinical decision rules by paramedics to determine which older person should stay at home or be transported to the Emergency Department (ED). ${ }^{38,39}$ Although neither of these studies explicitly assessed frailty among older adults, the outcomes of these studies were relevant to frail patients. ${ }^{38,39}$ One study from Canada assessed the performance of the Paramedic assessing Elders at Risk of Independence Loss (PERIL) rule which is a checklist of 43 yes/no questions for all older patients and not specific to trauma or fall mechanisms ${ }^{38}$ (Table 1). The study showed that the four-item PERIL prediction rule performed better than a proxy measure of paramedic clinical judgement and has more advantages over it as it has better prediction performance and has the ability to set different thresholds that meet the needs of the EMS service ${ }^{38}$ (Table 1). The Identifying Seniors at Risk (ISAR) tool, which is a screening tool that was developed to identify high-risk older patients in the ED, was applied by trained paramedics and showed to be a good alternative to the four-item PERIL tool as it had similar performance (AUC 0.57 vs 0.61 , respectively, $p=0.28$ ), however, the four-item PERIL tool is simpler and had better adherence. ${ }^{38}$ The other study from the UK evaluated the effectiveness, safety, and cost-effectiveness of the Computerized Clinical Decision Support (CCDS) for paramedics attending older people who fall. ${ }^{39}$ The study showed that the use of CCDS is safe, effective in referring older people who fall to community falls services and potentially costeffective $^{39}$ (Table 1).

Overall, frailty assessment in prehospital care was shown to be important, feasible, and maybe costeffective. This suggests that Integrating frailty assessment in prehospital triage could improve the accuracy of appropriate triage decisions and be more beneficial in terms of outcomes.

\section{Determining Appropriate Outcome Measures}

An outcome measure is referred to any measure that is chosen to assess the impact of interventions. ${ }^{40}$ It is a supposition that is the end point of an intervention. ${ }^{40}$ Therefore, it is important to measure the impact of interventions on outcomes. Mortality is an important Clinician Reported Outcome Measure (CROM) to improve trauma care for patients. It should be the primary focus when assessing trauma outcomes. For example, changing the trauma care system in the UK was shown to improve survival rates. ${ }^{41}$ However, reliance mostly on mortality as the primary outcome measure and not looking for other important secondary outcomes especially for older people seems to be inappropriate and could lead away from a focus on patient-centred care. A global health standard set of outcome measures in older persons which was relevant for people in the last 10 years of life was developed. ${ }^{42}$ It showed that older adults and their carers perceived survival to be less crucial than other outcome measures. $^{42}$ In fact, they consider mortality as an 
Table I The Use of Frailty Assessment Tools in Prehospital Care

\begin{tabular}{|l|l|l|}
\hline Study & Frailty Assessment Tool & Objective \\
\hline \multicolumn{2}{|l|}{ Frailty assessment tools in Prehospital Care. } & $\begin{array}{l}\text { To assess the perceptions of paramedic students about the application of the } \\
\text { EFS and GFI for assessing and screening older adults in the prehospital phase }\end{array}$ \\
\hline $\begin{array}{l}\text { Harris et al, } \\
(2018)^{37}\end{array}$ & $\begin{array}{l}\text { Edmonton Frail Scale (EFS) and the Groningen Frailty } \\
\text { Index (GFI) }\end{array}$ & \begin{tabular}{l} 
and \\
\hline
\end{tabular}
\end{tabular}

\section{- Main Findings:}

- In regard to the comprehensiveness, the GFI was considered to many of the participants to be superior over the EFS as it has great number of questions and include questions about daily living and activities.

- However, the EFS was considered by the participants to be more suitable for paramedics to assess frailty in the prehospital phase.

- The EFS was reported by the participants to be concise and its wording was reported as "relaxed and conversational, prompting, rather than intrusive" and "wording is better and can be easily worked into a normal history taking".

- Overall, the paramedic students in this study showed that there is a need to assess frailty in the prehospital phase and such assessment is applicable to be performed by paramedics.

\begin{tabular}{|l|l|l}
\hline $\begin{array}{l}\text { Goldstein } \\
\text { et al, }(2015)^{35}\end{array}$ & $\begin{array}{l}\text { Care Partner-derived Frailty Index based up on } \\
\text { Comprehensive Geriatric Assessment (CP-FI-CGA) }\end{array}$ & $\begin{array}{l}\text { To assess the validity of CP-FI-CGA for use in the EMS and Geriatric } \\
\text { Ambulatory Care (GAC). }\end{array}$ \\
\hline
\end{tabular}

\section{- Main findings:}

- It was shown to have good content, construct, and criterion validity.

- The mean CP-FI-CGA was $0.4 I \pm 0.15$. It was higher in the EMS group $(0.45 \pm 0.15)$ than in GAC $(0.37 \pm 0.14)(P<0.001)$.

- The CP-FI-CGA correlated well with the specialist completed FI-CGA $(0.7 ; \mathrm{P}<0.05)$.

- People who died had a higher CP-FI-CGA than survivors $(0.48 \pm 0.13$ versus $0.38 \pm 0.15)$.

- Higher CP-FI-CGA was reported in patients who died than those who survived $(0.48 \pm 0.13$ versus $0.38 \pm 0.15)$.

- With an increase in the frailty index by 0.01 , there was a higher risk of death [HR $(95 \% \mathrm{Cl}), 1.04(\mathrm{I} .02-\mathrm{I} .06)]$.

- However, the main limitation of this tool is that it was entirely dependent on the information from the care partner; older people who live independently without a care partner could not benefit from such assessment.

\begin{tabular}{|c|c|c|}
\hline $\begin{array}{l}\text { Goldstein } \\
\text { et al, }(2014)^{36}\end{array}$ & $\begin{array}{l}\text { Care Partner- Comprehensive Geriatric Assessment } \\
\text { (CP-CGA) }\end{array}$ & $\begin{array}{l}\text { - To assess the feasibility of care partners completing CGA and assess paramedics } \\
\text { comfort and perceived usefulness for using it in the prehospital phase. }\end{array}$ \\
\hline
\end{tabular}

\section{- Main Findings:}

- The study showed that applying this tool is feasible to assess and quantify frailty using the deficit accumulation method, based on the knowledge of the care partners.

- $92 \%$ of the care partners reported that they strongly agreed or agreed that the questions were clear and easy to understand.

- $87 \%$ of the care partners reported that the length of the survey was appropriate.

- $20 \%$ of them mentioned that some important aspects of health were not covered in the survey.

- All participating paramedics reported that frailty assessment and screening is valuable. 7I\% of them stated that using the CP-CGA could be effective in frailty screening.

- The reported barriers by the paramedics to enrol patients were the lack of a care partner present [n (\%), I5 (7I\%)], transport to a non-study hospital [n (\%), I I (52\%)], and lack of awareness [n (\%), 8 (38\%)].

Other tools related to frailty assessment in prehospital care.

\begin{tabular}{|l|l|l|l}
\hline $\begin{array}{l}\text { Lee et al, } \\
(2016)^{38}\end{array}$ & $\begin{array}{l}\text { Paramedic assessing Elders at Risk of Independence Loss } \\
\text { (PERIL) rule and Identifying Seniors at Risk (ISAR) tool. }\end{array}$ & $\bullet$ To derive and test the reliability and comparative effectiveness of PERIL rule. \\
\hline
\end{tabular}

\section{- Main Findings:}

- The PERIL rule is a checklist of 43 yes/no questions. Forty of the 43 items were shown to have good or excellent Inter-observer reliability.

- A four-item decision rule was derived: I) "Problems in the home contributing to adverse outcomes?" (Odds Ratio [OR] I.43); 2) "Called 9 II in the last 30 days?" (OR I.72); 3) “male” (OR I.38) and 4) "lacks social support” (OR I.4).

- The four-item PERIL prediction rule performed better than a proxy measure of paramedic clinical judgement (Area Under the Curve (AUC) 0.62 vs 0.57 , $P=0.02$ ) and has advantages over it as it has better prediction performance and has the ability to set different thresholds that meet the needs of the EMS service.

- The Identifying Seniors at Risk (ISAR) tool, which a predictive tool that was developed to identify high-risk older patients in the ED, was applied by trained paramedics and showed to be a good alternative to the four-item PERIL tool as it had similar performance (AUC 0.57 vs $0.6 \mathrm{I}$, respectively, $\mathrm{P}=0.28$ ), however, the four-item PERIL tool is simpler and had better adherence.

\begin{tabular}{|l|l|l|}
\hline $\begin{array}{l}\text { Snooks et al, } \\
(2014)^{39}\end{array}$ & Computerized Clinical Decision Support (CCDS). & $\begin{array}{l}\text { To evaluate the effectiveness, safety and cost-effectiveness of CCDS for } \\
\text { paramedics attending older people who fall. }\end{array}$ \\
\hline
\end{tabular}

(Continued) 
Table I (Continued).

\section{- Main Findings:}

- The findings of the study showed that the paramedics who applied the CCDS referred twice as many participants to falls services compared to the control paramedics (9.6\% vs $5.0 \%$ ) (OR $2.04,95 \% \mathrm{Cl} \mathrm{I.12}$ to 3.72 ).

- No adverse events were related to the group who had the CCDS assessment.

- The ambulance job cycle time was 8.9 minutes longer for patients who were assessed using the CCDS (95\% Cl 2.3 to 15.3 ).

- The average net cost saved by implementing the CCDS application was $£ 208$ per patient with existing electronic data capture, and $£ 308$ without.

inevitable and expected outcome. ${ }^{42}$ Outcomes that were considered important by older persons and their carers included:

(A) independence and living at own home,

(B) participation in social and community activities,

(C) quality of life and wellbeing,

(D) the avoidance of inappropriate discharge and readmission,

(E) isolation,

(F) loneliness and friendship,

(G) physical disabilities,

(H) hobbies and activities,

(I) access to 24 hours healthcare and social services,

(J) avoiding falls,

(K) delaying frailty,

(L) care and respite for the carer,

(M) malnutrition,

(N) physical symptom burden,

(O) pain,

(P) and sleep quality. ${ }^{42}$

In terms of outcomes following major trauma, an expert panel, which determined research priorities for older trauma patients, highlighted the need to determine appropriate outcome measures specifically for older people. ${ }^{28}$ They mentioned, for example, that the identification of polytrauma in older people living with frailty does not always change their outcomes, so in young trauma patients, we usually expect them to walk out of hospital and regain their full functional ability, while in these patients, we may rather look at their comfort and palliation. $^{28}$

Previous reviews showed that many outcome measurement tools are used in trauma registries to assess patient outcomes following trauma. ${ }^{43-46}$ For example, a recent scoping review showed that more than 100 unique measurement tools were used to assess Patient-Reported Outcome
Measures (PROMs) for hospitalized trauma patients. ${ }^{45}$ However, no study, to date, has investigated and validated the use of already existing outcome measure or developed an outcome measure specifically for older trauma patients. In the UK, a consensus study made recommendations on appropriate outcome measures for adults in general and pediatrics following major trauma, but no consensus has been made specifically for older adults. ${ }^{47}$

Therefore, it is important to assess CROMs and PROMs for older trauma patients as we need to look at both outcome measures in order to strike an ethical balance between paternalism (in healthcare provision) and autonomy (of the patient in what they expect and seek) when caring for this population.

\section{Outcomes Beyond Mortality for Older Trauma Patients}

For the assessment of outcomes beyond mortality for older trauma patients, outcomes including frailty, mental health, quality of life, overall health status, complications, use of healthcare services, in-hospital Length of Stay (LOS), readmission, functional status, and level of independence are all reported to be important (Table 2).

\section{Frailty and Overall Health Status}

Only one study from the UK assessed frailty during followup period and showed that patients aged $>75$ years with major trauma (Injury Severity Score [ISS] >15) had significant worsening of frailty at one-year after injury compared to pre-injury ( $8 \%$ of the study group were frail at pre-injury phase compared to $46 \%$ at one-year post injury). ${ }^{48}$ It also reported that $57 \%$ had positive comments on their mental health, quality of life, and functional status whereas $29 \%$ of the participants have negative comments on the same aspects at one-year following major trauma. ${ }^{48}$ Inaba et al ${ }^{49}$ showed a significant decline in seven of eight health domains using the 36-item Short Form survey (SF-36) at 2.8 years after 
Table 2 Outcomes Beyond Mortality for Older Trauma Patients

\begin{tabular}{|l|l|l|l|}
\hline Study & Population & No. of Patients & Follow-Up Period \\
Collection \\
Period
\end{tabular}

- Findings:

- At one year after admission, 34 of 79 patients (43\%) died, 17 were lost to connect or declined to participate. The remaining 28 patients were reviewed and followed up.

- A significant worsening of frailty $-46 \%$ at one year versus $8 \%$ prior to the major trauma.

- $57 \%$ of the patients in this study had positive comments on their current conditions including being alive and surviving their injuries, thankful for their care especially with their discharge to their own homes, and return to work which indicates maintaining independence.

- On the other hand, $29 \%$ of the participants had negative comments on their current status following injury including ongoing anxiety and frustration, loss of independence and inability to perform previous tasks and hobbies, inability to return to work, feeling of isolation, low mood, and depression.

\begin{tabular}{|l|l|l|l|}
\hline $\begin{array}{l}\text { Alavi et al, } \\
(2014)^{60}\end{array}$ & $\begin{array}{l}>60 \text { years with limb trauma, no dementia, and } \\
\text { independent prior to injury. }\end{array}$ & 200 & Three months post injury. \\
\hline
\end{tabular}

- Findings:

- According to the Independency Scale of Activities of Daily Living (ISADL), I6I (8I\%) of the patients were completely independents, 34 (I7\%) were relatively independents, 5 (3\%) were relatively dependents, and none was completely dependent prior to injury.

- The level of independency decreased at one-month post injury as 27 (14\%) of the patients were completely independents. Fifty (25\%) patients were relatively independents, 116 (58\%) were relatively dependents, and 7 (4\%) were completely dependents.

- At 3 months follow-up post injury, the ISADL slightly improved as 45 (22.5\%) patients were completely independents, 9 I (46\%) were relatively independents, 53 (27\%) were relatively dependents, and II (6\%) were completely dependents.

\begin{tabular}{|c|c|c|c|c|}
\hline $\begin{array}{l}\text { Kelley- } \\
\text { Quon et al, } \\
(2010)^{59}\end{array}$ & $\begin{array}{l}\geq 65 \text { years trauma patients who had a completed Short } \\
\text { Functional Status questionnaire (SFS) at } 3,6 \text {, and } 12 \\
\text { months post injury (Longitudinal (L) group) (ISS mean } \\
=12 \text { ) and } \geq 65 \text { years trauma patients who reported their } \\
\text { preinjury functional status using the SFS at hospital } \\
\text { admission (Control (C) group) (ISS mean }=14 \text { ) }\end{array}$ & $\begin{array}{l}78 \text { trauma patients from } \\
\text { (L) group and } 92 \text { trauma } \\
\text { patients from (C) group. }\end{array}$ & 3,6 , and 12 months post injury. & $\begin{array}{l}\text { From December } \\
2006 \text { to } \\
\text { November } 2007\end{array}$ \\
\hline
\end{tabular}

\section{- Findings:}

- Of the 78 patients from L group, 8 (10\%) died during their hospitalization and 10 (13\%) died post discharge and before being interviewed.

- Of the remaining 60 patients from L group, 47 (79\%) were successfully contacted by phone for follow-up, of which 37 agreed to participate for at least one interview (response rate, 62\%).

- For the C group, 64 interviews were conducted and completed over 12 months post injury. 63 of 92 (69\%) eligible trauma patients completed a preinjury functional survey.

- According to the demographics and clinical characteristics between the two groups, there were no differences in the baseline variables like age, ethnicity, ISS, Charlson Comorbidity Index $(\mathrm{CCl})$, and living status prior to injury $(\mathrm{P}>0.05)$. The difference was found only in gender $[\mathrm{C}$ group $(69 \%$ male participants) vs $L$ group ( $46 \%$ male participants), $P=0.02)$.

- At time of discharge, 23 (62\%) patients from L group were discharged home, 5 (14\%) were discharged to an acute rehabilitation centre, 6 (I6\%) were discharged to a nursing home, and $3(8 \%)$ were transferred to another hospital.

- Of the 37 trauma patients from L group, 35 (95\%) were contacted at 12 months, of which 34 (97\%) were living at home. The remaining one patient was transferred to a hospital at one-year post injury from a nursing home. The two patients who did not respond to the survey at 12 months, one changed the place of residence out of the country (USA) and the other declined to complete the survey at 6 and 12 months.

- The SFS questionnaire was applied in this study. It is a self-reported measurement tool of the individual's ability to perform five Activities of Daily Living (ADL) (shopping, bathing, walking, light housework, and managing finances). The tool gives results from 0 to 5 (5 means independent in all 5 activities).

- In the $C$ group, the average $A D L$ was $4.6(S D=0.9)$ with 50 of $63(79 \%)$ trauma patients scoring 5 out of 5 possible points.

- In the $\mathrm{L}$ group, the average $\mathrm{ADL}$ was $4.2,4.2$, and $4.3(\mathrm{SD}=0.9)$ for each interviewed group at 3,6 , and $\mathrm{I} 2$ months.

- The study examined the decline in the number of ADLs by calculating the difference between $C$ group and $L$ group scores. This revealed that a total of one ADL was lost at 12-month follow-up post injury.

- The study also showed that the magnitude of this decline at I2-month follow-up was twice the decline at 3-month follow-up (I ADL vs 0.5 ADL).

\begin{tabular}{|c|c|c|c|c|}
\hline $\begin{array}{l}\text { Inaba et al, } \\
(2003)^{49}\end{array}$ & $\geq 65$ years injured patients. (ISS mean $=21.4 \pm 10.5$ ) & 171 & $\begin{array}{l}\text { The mean follow-up period was } \\
2.8 \text { years (range, I.5-4.5 years). }\end{array}$ & $\begin{array}{l}\text { From April I, } \\
\text { 1996, to March } \\
31,1999 .\end{array}$ \\
\hline
\end{tabular}

(Continued) 
Table 2 (Continued).

\section{- Findings:}

- Following trauma, $82 \%$ of the patients in the study had physiotherapy and occupational therapy during their initial hospitalization. Eighty-one percent of these continued to had rehabilitation post discharge.

- Older patients aged $\geq 65$ years had a LOS in-hospital of $22 \pm 33$ days compared to those aged $<65$ years ( $15 \pm 20$ days) $(P<0.001)$.

- $14 \%$ of the patients were still having rehabilitation at long-term follow-up.

- $36 \%$ of the study patients were discharged home at various levels of care, $32 \%$ were discharged to a specialized rehabilitation unit, $24 \%$ were discharged to a local acute care hospital, and $9 \%$ were discharged to a chronic care institution.

- Prior to trauma, 125 (98\%) of the study patients lived independently at home, only one patient had home care, and two patients were dependents on a spouse due to at least one of the following reasons: meal preparation, household cleaning and maintenance, personal care, and medication administration.

- By using these exact criteria, only $80(63 \%)(P<0.001)$ of the study patients at the long-term follow-up post trauma were independent at home. The remaining patients were dependents at various level, with $26(20 \%)$ relying on home care, $5(4 \%)$ relying on a spouse, $9(7 \%)$ relying on a family member, and $8(6 \%)$ relying on nursing care at an institution.

- For the SF-36:

- A statistically significant decline was found in seven of eight health domains when injured patients were surveyed at 2.8 years post trauma in comparison to non-injured Canadian residents of the same age [(Physical Functioning, Role-Physical, General Health, Vitality, Social Functioning, and Mental Health; $\mathrm{P}<0.05$ ), (Role-Emotional; $\mathrm{P}<0.001$ )].

- No difference was noted in regard to the level of bodily pain between injured patients 2.8 years post trauma in comparison to non-injured Canadian residents of the same age.

- As age increased in the injured patients' group, the levels of mental and physical health measures in all domains except for bodily pain decreased.

A statistical significance was only seen between age groups in the domain of physical functioning $(P<0.05)$.

- Men had higher scores than women in all domains, but the difference was not statistically significant.

\begin{tabular}{|c|c|c|c|c|}
\hline $\begin{array}{l}\text { McKevitt } \\
\text { et al, } \\
(2003)^{51}\end{array}$ & $\begin{array}{l}\text { Geriatric patients ( } \geq 65 \text { years) and adult patients (age } \\
20-30 \text { years) with an ISS }>15 \text { (ISS mean for geriatrics } \\
=27.3 \text {, ISS mean for adults }=26.3 \text { ). }\end{array}$ & $\begin{array}{l}40 \text { geriatric patients and } \\
44 \text { adult patients. }\end{array}$ & $\begin{array}{l}\text { Two years follow-up post } \\
\text { discharge. }\end{array}$ & $\begin{array}{l}\text { Between } \\
\text { July } 1997 \text { and } \\
\text { March } 1998\end{array}$ \\
\hline
\end{tabular}

\section{- Findings:}

- 39 out of 40 (98\%) of the geriatric patients were living independently at time of admission compared to 44 of 44 (I00\%) of adult patients.

- Thirty-seven complications were reported in 20 older trauma patients whereas only I3 complications were reported in 12 younger adults $(\mathrm{P}<0.00 \mathrm{I})$

- 20 (50\%) geriatric patients experienced complications following trauma compared to 12 (27\%) adult patients. 17 geriatric patients had serious complications which included respiratory failure, cardiac dysfunction, pneumonia, renal failure, delirium and alcohol withdrawal in comparison to only 6 younger adults $(P<0.001)$.

- Functional status at time of admission and discharge of both groups were measured as the following:

- Three geriatric patients (8\%) died compared to two adult patients (5\%) $(P=0.29)$.

- 14 (35\%) geriatric patients were discharged home compared to $22(50 \%)$ adult patients $(P=0.056)$.

- II (28\%) geriatric patients were transferred to a rehabilitation facility compared to I5 (34\%) adult patients $(P=0.30)$

- Seven (18\%) geriatric patients were transferred to an acute care hospital closer to home compared to five $(11 \%)$ adult patients $(P=0.19)$.

- Five (13\%) of geriatric patients were transferred to a nursing home and no adult patients were transferred (P=0.007).

- When patients' family physicians were contacted two years post discharge, information was available for only 12 of 25 (48\%) patients who were either discharged home or rehabilitation facilities.

- Most of the 12 patients had positive functional outcomes as 9 (75\%) were still living independently compared to 2 (I7\%) who died, and only I (8\%) was living in a nursing home.

- Older trauma patients had lengthier in-hospital stay than younger patients [34.5 days (95\% Cl: $24-44)$ vs 21.6 days (95\% Cl: I5-28) $(\mathrm{P}=0.05)$ ].

- Seven (I8\%) of older trauma patients required admission to ICU compared to II (25\%) of younger patients $(P=0.22)$.

- The mean LOS in the ICU was 1.65 for older trauma patients and 2.79 for younger patients $(P=0.70)$.

\begin{tabular}{|c|c|c|c|c|}
\hline $\begin{array}{l}\text { Ferrera } \\
\text { et al, } \\
(1999)^{52}\end{array}$ & $\begin{array}{l}\geq 65 \text { years injured patients who were treated and } \\
\text { discharged from the Emergency Department (ED). }\end{array}$ & 105 & $\begin{array}{l}\text { Follow-up ranged from } 30 \text { to } \\
\text { I } 47 \text { days, with a mean of } 49 \\
\text { days post discharge. }\end{array}$ & $\begin{array}{l}\text { From } \\
\text { September 15, } \\
\text { 1996, until } \\
\text { August 31, } 1997\end{array}$ \\
\hline
\end{tabular}

(Continued) 
Table 2 (Continued).

\section{- Findings:}

- Based on ADL testing, the study defined good outcomes as no or minor discomfort and resuming normal activities were reported, fair outcomes as continued moderate pain that limited ADL was reported, and poor outcomes as very limited abilities to perform ADL was reported or if a deterioration in the health status of the patient was experienced.

- 105 patients were included in the study of which 5 patients were lost to follow-up. In the remaining 100 patients who were followed-up, 88 ( $88 \%$ ) had good outcomes, 9 (9\%) had fair outcomes, and only $3(3 \%)$ had poor outcomes.

- Poor outcomes among the 3 (3\%) patients were not related to their injuries; one patient with diabetes mellitus, dementia, and Parkinson's disease was admitted 5 weeks following trauma for pneumonia; a second patient with coronary artery disease and glaucoma had a stroke and paralysis within I month of injury; and a third patient with atrial fibrillation and cerebrovascular disease was admitted with pneumonia 5 weeks following trauma and died within 5 days.

- The study reported complications of the patients following trauma which revealed two extremity infections and one poorly healing wound.

- Eleven ( $11 \%$ ) of the patients who were followed-up were admitted in the ED at the first 30 days following trauma, of which 6 (55\%) of them had problems related to their initial injury or its management.

\begin{tabular}{|c|c|c|c|c|}
\hline $\begin{array}{l}\text { Battistella } \\
\text { et al, } \\
(1998)^{57}\end{array}$ & $\geq 75$ years injured patients (ISS mean $=9.4 \pm 7.7$ ) & 279 & $\begin{array}{l}\text { Minimum of } 4 \text { years }(5.4 \pm \text { I.I } \\
\text { years) }\end{array}$ & $\begin{array}{l}\text { Between June } \\
1988 \text { and July } \\
1992\end{array}$ \\
\hline
\end{tabular}

- Findings:

- Of the 93 patients who were contacted following injury, most of them described their health as excellent (16\%) or good (42\%). Others reported their health as fair (28\%) and only a small percentage of these patients described their health as poor (I4\%).

- $29 \%$ of these patients required hospitalization at least once or more in the year prior to the survey and only $16 \%$ reported more than six physician visits in the past year.

- Of the 93 patients in the study who were contacted, $33(\approx 35 \%)$ reported no difficulties in the performance of 14 activities in the assessment of ADL and $57 \%$ reported no difficulties in the performance of 12 or more of the 14 activities of ADL testing.

- The most common activities where difficulties were reported include transportation (52\%), shopping (45\%), housekeeping (39\%), and food preparation (38\%).

- The mean LOS in-hospital was $13 \pm 26$ days (range, 0-249 days).

- The overall mean LOS in the ICU was $5 \pm 14$ days (range, $0-146$ days), with a mean LOS in the ICU of I3 \pm 21 days for patients who were admitted to the ICU at some point during their hospitalization.

\begin{tabular}{|l|l|l|l}
\hline $\begin{array}{l}\text { van der } \\
\text { Sluis et al, } \\
(1996)^{55}\end{array}$ & $\begin{array}{l}\text { Adult patients with major trauma (ISS }>15) . \text { older trauma } \\
\text { patient }(\geq 60 \text { years) (ISS mean, survivors }=23.9 \text { and non- } \\
\text { survivors }=34.3) \text { and younger trauma patients }(20 \text { to } 29 \\
\text { years) (ISS mean, survivors }=29.6 \text { and non-survivors }=37.7)\end{array}$ & $\begin{array}{l}121 \text { older trauma } \\
\text { patients and } 167 \text { younger } \\
\text { adult trauma patients. }\end{array}$ & $\begin{array}{l}\text { From January } \\
1985 \text { to January } \\
1990\end{array}$ \\
\hline
\end{tabular}

\section{- Findings:}

- At time of discharge:

- $38 \%$ younger patients discharged home compared $34 \%$ older patients.

- $44 \%$ younger patients were discharged to a rehabilitation centre compared to only $14 \%$ older patients $(P<0.05)$.

- A large group of older patients were discharged to a nursing home (34\%) in comparison to only $3 \%$ younger patients $(P<0.05)$.

- The remaining patients were discharged to another hospital (I8\% younger patients vs II\% older patients) or to a psychiatric care centre ( $1 \%$ younger patients vs $4 \%$ older patients).

- At two-year follow-up post trauma, there was no significant difference between the two patient groups in regard to the proportion of the patients who recovered completely or had minimal disability (ie, Glasgow Outcome Scale [GOS] score 5) (65\% of the younger patients vs $74 \%$ of the older patients).

- $15 \%$ of older patient had fewer moderate disabilities (GOS score 4 ) than $24 \%$ of the younger patients $(P<0.05)$.

- No signinifcant difference in severe disabilities (GOS score 3 ) between older patients (2\%) and younger patients (7\%).

- At two years post discharge from hospital, 7 patients died; they were all from the older patient group. Four of them died as a result of their injuries and the remaining 3 died of natural causes.

- At two years post trauma, none of the patients was still in a persistent vegetative state.

- The younger group had shorter LOS in ICU (mean, survivors $=9.1$ days, non-survivors $=3.4$ days) than older adults (mean, survivors $=13.5$ days, nonsurvivors $=14.6$ days) and also in-hospital (mean, survivors $=28.6$ days, non-survivors $=2.6$ days) versus older adults (mean, survivors $=32.2$ days, nonsurvivors $=14.4$ days $)(P<0.05)$.

- For older trauma patients, the duration of staying ventilated and hospitalized increased with age.

\begin{tabular}{|l|l|l|l|}
\hline $\begin{array}{l}\text { Day et al, } \\
(1994)^{58}\end{array}$ & $\begin{array}{l}>60 \text { years injured patients with an ISS }>15 \text { (ISS mean } \\
=25) .\end{array}$ & 118 & $\begin{array}{l}\text { Minimum of 2-year follow-up } \\
\text { (Average of } 3 \text { years after } \\
\text { admission). }\end{array}$ \\
\hline
\end{tabular}

(Continued) 
Table 2 (Continued).

\section{- Findings:}

- Of the 118 patients, 36 (31\%) died in hospital. 81 of the 82 patients who survived were followed-up.

- Additional 25 patients died during the follow-up period of the study; three aged $6 \mathrm{I}-70$ years and 22 aged $>70$ years $(\mathrm{P}<0.000 \mathrm{I})$.

- The study showed that $43 / 53(81 \%)$ patients who survived at long term following major trauma returned to continue their lives independently.

- Based on ADL testing, $41 / 54$ (76\%) patients achieved the maximum score in the test.

\begin{tabular}{|l|l|l|l|l|}
\hline $\begin{array}{l}\text { Zietlow } \\
\text { et al, } \\
(1994)^{54}\end{array}$ & $\begin{array}{l}\geq 65 \text { years with an ISS } \geq 10 \text { and admitted with } \\
\text { multisystem trauma (ISS mean =18) (ISS range, 10-57). }\end{array}$ & 94 & $\begin{array}{l}\text { Mean of follow-up was } 12 \\
\text { months (range, 6-18 months). }\end{array}$ & $\begin{array}{l}\text { From January } \\
\text { 199| through } \\
\text { December 1991 }\end{array}$ \\
\hline
\end{tabular}

\section{- Findings:}

- The study included 94 patients, of which 66 (70\%) were independents, I4 (15\%) were dependents, and 14 were (15\%) partially dependents prior to injury.

- At the time of discharge, 72 patients survived their injuries. Of these patients, 38 (53\%) were discharged home (25 [35\%] were independents). The remaining 13 patients were discharged home with a requirement of temporary nursing care at home in addition to five patients who were partially dependents (a total of 18 [25\%] were partially dependents). Of these five patients, three were discharged to a transitional care unit, one to a rehabilitation unit, and one to an intermediate care facility. At last, the remaining 29 (40\%) of the 72 patients were dependents at time of discharge (26 patients required nursing home care and three required transfer to other hospitals).

- At time of follow-up, 56 of the 72 patients responded to the questionnaire (seven patients died, two lost to follow-up, and seven rejected to participate). Of these, $38(69 \%)$ were living at home as independents, $14(26 \%)$ remained in a nursing home as dependents, and $3(5 \%)$ were partially dependents at transitional facilities.

- Sixty-eight percent of the patient rated their health status as good to excellent.

- Ninety-four percent of the patients reported that they were able to return back to their normal level of activity.

- The admission to surgical ICU was required for 35 (37\%) patients for the following interventions: mechanical ventilation, 24; antiarrhythmic drugs, I6; and inotropic support, 12.

- The mean LOS at surgical ICU was 7.7 days (range I-54 days).

- The mean LOS in-hospital for all patients was 10 days (range 0-95 days)

- 36 of $94(38 \%)$ patients required surgical treatment; 10 procedures were emergency, 10 were urgent, and 16 were elective.

- The most common procedure performed for these patients was fracture management via open reduction and internal fixation in 19 cases, followed by evacuation of subdural hematomas in eight cases.

\begin{tabular}{|l|l|l|l|l|}
\hline $\begin{array}{l}\text { Carrillo } \\
\text { et al, } \\
(1993)^{53}\end{array}$ & $\begin{array}{l}\geq 65 \text { years with blunt trauma. Excluded burns, } \\
\text { penetrating, isolated orthopedic injury, and patients with } \\
\text { minimal injuries }\end{array}$ & 94 & 1 to 3 years post discharge. & $\begin{array}{l}\text { From July } 1986 \\
\text { to December } \\
1988\end{array}$ \\
\hline
\end{tabular}

\section{- Findings:}

- Of the 94 included patients in the study, 56 (60\%) required ICU admission.

- An average of 3.4 operations per patient was identified.

- Of the 94 patients, 12 died; 6 within the first 48 hours of hospital admission.

- Among the survivors, more than $70 \%$ were able to be independent post discharge from the hospital.

- Of the 22 patients who required institutional care post discharge, $12(56 \%)$ were able to return home.

- The study showed high survival rate $(87 \%)$ and rate of patients living at home post discharge $(87 \%)(70 \%$ rate of independence after discharge).

\begin{tabular}{|l|l|l|l|l|}
\hline $\begin{array}{l}\text { van Aalst } \\
\text { et al, } \\
(199 \mid)^{61}\end{array}$ & 265 years with blunt trauma and an ISS $>15$. & $\begin{array}{l}105 \text { (7 lost to follow-up). } \\
98 \text { patients were } \\
\text { included in the study. }\end{array}$ & $\begin{array}{l}\text { At least one year up to } 6 \text { years } \\
\text { follow-up post discharge (mean } \\
\text { follow-up time }=2.82 \text { years). }\end{array}$ & $\begin{array}{l}\text { From } \\
\text { August 1984 to } \\
\text { June } 1989\end{array}$ \\
\hline
\end{tabular}

\section{- Findings:}

- Of the 98 patients included in the study, 44 died in-hospital and 54 survived at discharge.

- Of the 54 survived patients, 48 were interviewed as 6 patients died post discharge (all 6 patients died within 2 years post discharge)

- At the time of interviewing the 48 survived patients, 32 (67\%) were independents and $16(33 \%)$ were dependents.

- The study further classified these patients as follows:

- 8 (17\%) were independents with maintained function.

- $24(50 \%)$ were independents with declined function.

- $10(21 \%)$ were moderately dependents with declined function.

- 6 (13\%) were custodial (patients who were bedridden, incapable of feeding or toileting themselves, or in a nursing home). 
Table 2 (Continued).

\begin{tabular}{|c|c|c|c|c|}
\hline & & & & \\
\hline \multicolumn{5}{|c|}{ 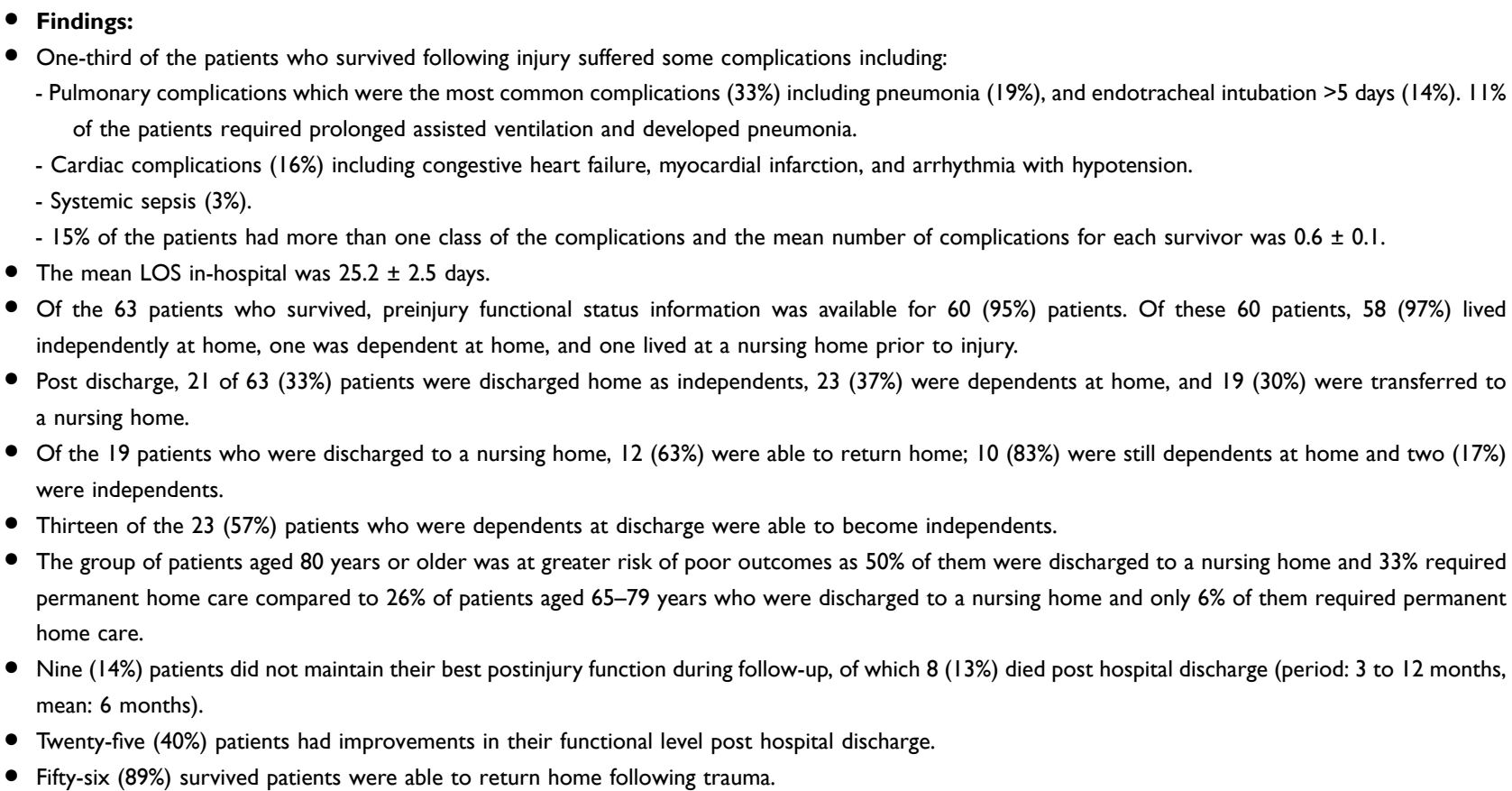 } \\
\hline & & U & $y$. & \\
\hline \multicolumn{5}{|c|}{$\begin{array}{l}\text { - Findings: } \\
\text { - One hundred patients were included in the study, of which ninety-six ( } 96 \%) \text { patients were independents prior to injury. This means that they did not } \\
\text { require professional assistance with performing their daily activities. Four ( } 4 \% \text { ) patients required nursing visits for assistance or meals preparation. No } \\
\text { patients were living at a nursing home or required full nursing care prior to injury. } \\
\text { - At one-year follow-up, } 85 \text { patients survived post injury, of which only seven patients ( } 8 \%) \text { were independents, } 17 \text { (20\%) required nursing visits for assistance } \\
\text { or meals preparation, and } 61 \text { ( } 72 \%) \text { required full nursing care. } \\
\text { - The survivors stayed at hospital for } 23 \text { days compared to non-survivors ( } 19 \text { days). } \\
\text { - The major note is that survivors spent an average of two days in the ICU compared to } 16 \text { days for non-survivors. } \\
\text { - } 90 \% \text { of the non-survivors' hospitalization time was spent in the ICU. } \\
\text { - As non-survivors spent most of their hospitalization period in the ICU, that reflected on the cost of their treatment as the mean cost per patient was } \\
\$ 23,003 \text { compared to } \$ 13,158 \text { for the survivors. }\end{array}$} \\
\hline
\end{tabular}

trauma for trauma patients aged $\geq 65$ years compared to noninjured residents of the same age (Table 2).

\section{Complications}

Few studies reported serious complications of older patients following trauma including pulmonary complications, cardiac complications, systematic sepsis, renal failure, delirium, and alcohol withdrawal (Table 2).$^{50,51}$ When compared to younger adults, older trauma patients who survived following trauma had significantly higher serious complication rates. ${ }^{51}$ Lower rates of complications related to injury were reported for older patients discharged from the ED including extremity infection and poorly healing wounds (Table 2). ${ }^{52}$

\section{Use of Healthcare Services}

With regard to the use of healthcare services, more than $80 \%$ of the older trauma patients required rehabilitation (physiotherapy or occupational therapy) extending beyond discharge from the hospital. ${ }^{49}$ An average of 3.4 operations 
were performed per patient for trauma patients aged $\geq 65$ years. ${ }^{53}$ Thirty-eight percent of trauma patients with ISS $\geq 10$ required surgical treatment (Table 2) ${ }^{54}$ The most common performed procedure for these patients was fracture management via open reduction and internal fixation (Table 2). ${ }^{54}$

Sixty percent of trauma patients aged $\geq 65$ years required Intensive Care Unit (ICU) admission. ${ }^{53}$ Previous evidence showed no significant change in ICU admission between older and younger trauma patients ${ }^{51,55}$ (Table 2). Older adults with major trauma (ie, ISS $>15$ ) stayed ventilated in the ICU for longer periods than younger patients and the duration of staying ventilated increased with age ${ }^{55}$ (Table 2). For the use of surgical ICU, $37 \%$ of trauma patients aged $\geq 65$ years with an ISS $\geq 10$ were admitted for the following interventions: mechanical ventilation, antiarrhythmic drugs, and inotropic support. ${ }^{54}$

An earlier study showed that $90 \%$ of hospitalization time for non-survivor older trauma patients aged $>70$ years was spent in the ICU. ${ }^{56}$ This reflected on the cost of their treatment as the mean cost per patient was $\$ 23,003$ compared to $\$ 13,158$ for the survivors. ${ }^{56}$

\section{Length of Stay}

Variation in hospital LOS for older trauma patients ranges from a mean of 10 days to 35 days (Table 2). ${ }^{4-51,54-57}$ Older trauma patients significantly stayed for longer period in-hospital than younger patients even after major trauma (ie, ISS >15) (Table 2). ${ }^{49,51,55}$ Furthermore, older patients with an ISS $>15$ who survived had lengthier in-hospital stay than younger adults and also the same is true for those who did not survive ${ }^{55}$ (Table 2). For patients aged $>70$ years, those who survived had a mean LOS of 23 days compared to 19 days for non-survivors. ${ }^{56}$

Differences in ICU LOS were identified in the literature ranging from a mean of 2 days to 16 days ${ }^{51,54-57}$ (Table 2). One study showed that patients aged $\geq 65$ years with an ISS $>15$ had shorter LOS in ICU than younger patients aged 20-30 years old $(\mathrm{P}=0.70) .{ }^{51}$ However, another study showed significantly increased LOS in ICU for older patients who survived and who did not survive compared to younger patients after major trauma (ie, ISS $>15)(\mathrm{P}<0.05)^{55}$ (Table 2). Older trauma patients aged $>70$ years who survived spent an average of two days in the ICU compared to 16 days for those who did not survive. ${ }^{56}$

\section{Readmission and Hospitalization}

A previous study, which followed-up older trauma patients for a mean length of $5.4(\mathrm{SD} \pm 1.1)$ years, found that $29 \%$ of trauma patients aged $\geq 75$ years required hospitalization at least once in the year preceding the survey. ${ }^{57}$ It also showed that $16 \%$ of the patients reported more than six physician visits in the previous year. ${ }^{57}$ Of injured patients aged $\geq 65$ years and discharged from the ED, $11 \%$ were admitted to the ED at the first 30 days following trauma, of which $55 \%$ had problems related to their initial injury or its management (Table 2). ${ }^{52}$

\section{Functional Status and Level of Independence}

For the assessment of functional status, Oreskovich et $\mathrm{al}^{56}$ showed that more than $90 \%$ of trauma patients aged $>70$ years with "severe" injuries (ISS mean $=19$ ) required nursing care at home or in a nursing care facility. The studies published after that, however, showed more promising results, with $70 \%$ or more of older patients with different ISS means returning to live independently at home (Table 2). ${ }^{50,51,55,58,59}$ Others also reported much higher rates of independence and living at home than the earlier study by Oreskovich et $\mathrm{al}^{56}$ (Table 2). ${ }^{4,49,52-54,57,60,61}$ Although improvements in the level of independence and living at home were reported at different follow-up periods, it did not reach the pre-injury level (Table 2). ${ }^{4-51,54,60}$ Progressive deterioration in functional ability for older trauma patients at one-year follow-up was reported ${ }^{59}$ (Table 2). However, comparing the results of functional status for older trauma patients is difficult due to the recruitment of different patient populations (age group, pattern of injury, and injury severity), applying different follow-up periods (ranging from a mean of 49 days up to 5 years), not using standardized measures, variable definitions of "independence", and many studies were published more than a decade ago (Table 2).

Overall, the findings of these studies indicate the importance of measuring outcomes other than mortality for older trauma patients. These could include outcome measures looking into independence and living at own home, frailty, cognition and mood, social networking and support, complications, and use of healthcare services, LOS, and readmissions.

\section{Prehospital Triage and Outcomes}

The impact of prehospital triage decisions on outcomes of older trauma patients is still uncertain. ${ }^{3,5,10,15}$ Most of current prehospital triage tools were assessed for their 
accuracy in identifying major trauma among older people ${ }^{4,6,8,9,11,12,14,17,62}$ and only few were assessed for their effects on the outcomes, with mortality used as the main outcome measure. , $^{3,7,10,13,15,63,64}$ Other outcomes including disability, complications, costs, LOS, and discharge to home were rarely captured in the assessment of triage tools. ${ }^{7,10,15,63}$ No standardized patient outcome measures regarding functional status, quality of life, and wellbeing for older trauma patients were reported in these studies.

\section{Determining the Benefits of Major Trauma Centres Access}

There is still no strong consensus if triaging older trauma patients to MTCs is beneficial (Table 3). In terms of mortality, a recent evidence showed that older trauma patients were under-triaged, ie, had lower odds of MTC transport (adjusted OR $0.52,95 \%$ CI $0.35-0.78$ ) than younger adults and this was associated with 1.7 times increase in their in-hospital mortality $(95 \%$ CI 1.04-2.7). ${ }^{3}$ Furthermore, a previous study showed that under-triaged older trauma patients had higher mortality than under-triaged younger patients $(21 \%$ vs $6.0 \%$, respectively). ${ }^{10}$ However, Staudenmayer et al ${ }^{15}$ investigated the unadjusted 60-day mortality rate for older trauma patients with an ISS $>15$ and found no significant difference between patients who were transported to non-MTCs compared to those transported to MTCs $(16 \%$ vs $17 \%$, $\mathrm{p}=0.87$ ). They also showed that the transportation of this population to MTCs is associated with higher costs [Total costs, \$, median (Interquartile Range [IQR]): 35,069 (19,$321-88,357)$ vs $14,332(5112-29,321)]$ and prolonged inhospital LOS [LOS, days, median (IQR): $6.0(3.0-14.0)$ vs $5.0(1.5-8.0)] .{ }^{15}$ The study, however, did not adjust for comorbidities and there was no consideration of specific patterns of injury such as head injury. ${ }^{15}$ The study also performed mortality analysis based on only 41 deaths which may have impacted the precision of the estimated effect. $^{15}$

A recent study, which assessed the impact of specific geriatric trauma triage criteria on outcomes found no significant difference in mortality rate before its application (7.1\%) (95\% CI, 6.6-7.4\%) compared to post application (6.6\%) (95\% CI, 5.9-6.6\%) despite identifying more older trauma patients who required MTC transport (improved sensitivity from $61 \%$ to $93 \%$ after applying the criteria). ${ }^{63}$ It also showed minimal increase in the rate of older trauma patients discharged home from $34 \%$ (95\% CI $33-35 \%)$ to $35 \%$ (95\% CI, 35-35\%) (difference 1.2\%, 95\% CI of the difference $0.2-2.2 \%) .{ }^{63}$ However, the results of this study may have been influenced by destination compliance as initial transportation to MTCs improved by only $1 \%$ after the application of the developed triage tool $(45 \%$ vs $44 \%){ }^{63}$ "Destination compliance" is simply defined as access to the highest level of trauma services for patients who meet the prehospital trauma triage criteria. Another study showed higher disability rates $(22 \%$ vs $6.0 \%)$ and complication rates (39\% vs $23 \%$ ) in older trauma patients triaged to lower MTCs in comparison with their younger counterparts. ${ }^{10}$

As previous literature looking into the benefits of prehospital triage of older trauma patients to MTCs showed conflicting findings, these findings echo the broader literature, which showed no strong consensus about the impact of conveyance to MTCs for older people with trauma (Table 3). The literature review showed that most of the previous evidence investigated the benefits of older trauma patients' access to MTCs with regards to their survival or mortality. Other outcomes that were rarely measured regarding the benefits of MTC access for older trauma patients included LOS, complications, and discharge to home. No patient outcomes were measured in the previous literature to assess the benefits of MTC access including outcomes related to mental health, functional ability, and quality of life. Such outcomes were shown in the previous section to be important to measure when caring for older trauma patients.

Previous evidence showed survival benefit for the treatment of older trauma patients of different age groups at MTCs compared to non-MTCs (Table 3) ${ }^{65-67}$ However, some other studies showed no significant advantage of such access for older trauma patients ${ }^{68}$ and that the treatment at non-MTC was associated with more than 4-fold increase in the likelihood of survival (Table 3). ${ }^{69}$ It was shown that the admission of older trauma patients to MTCs was associated with lengthier in-hospital stay than non-MTCs (Table 3). ${ }^{69}$ Smith et $\mathrm{al}^{70}$ showed that the treatment of patients aged $>55$ years at MTCs was associated with lower rates of complications than those treated at non-MTCs (Table 3). The level of care, however, was not associated with discharge to home rates (Table 3). ${ }^{69}$

Although most of these studies showed some benefit of MTC access for older adults, generalizing these results may not be appropriate as these studies had variations in the datasets that were used for analysis, included different patient 
Table 3 Benefits of MTC Access for Older Trauma Patients

\begin{tabular}{|l|l|l|l|}
\hline Study & Population & $\begin{array}{l}\text { No. of } \\
\text { Patients }\end{array}$ & Measured Outcomes \\
\hline $\begin{array}{l}\text { Garwe } \\
\text { et al, } \\
(2020)^{65}\end{array}$ & $\geq 55$ years trauma patients with at least an ISS of 9. & 25,288 & 30 -day in-hospital mortality. \\
\hline
\end{tabular}

\section{- Findings:}

- Patients treated at MTCs had longer length of in-hospital stay (mean [ \pm SD], 7.6 [7.2] vs $5.8[5.6], P<0.000 \mathrm{I}$ ) and higher proportion of overall unadjusted mortality compared to patients treated at non-TCs (number [\%], III8 [10.2\%] vs $108 \mathrm{I}[7.5 \%], \mathrm{P}<0.000 \mathrm{I}$ ).

- The majority of deaths in both groups occurred within 7 days of hospital admission (805 [72\%] deaths at MTCs and 817 [75.6\%] at non-TCs).

- The analysis of 7-day survival, after the adjustment for potential confounders, showed that the treatment of patients at MTCs was significantly associated with lower rates of death and was more significantly stronger for patients aged <65 years (HR [95\% Cl], 0.45 [0.36-0.56]) compared to patients aged $\geq 65$ years (HR [95\% Cl], 0.65 [0.58-0.73]).

- Beyond 7 days, the survival benefit of the treatment at MTCs was observed (HR [95\% Cl], 0.68 [0.56-0.83]). The treatment at non-MTCs was associated with constantly higher 30-day cumulative risk of death.

- Of the study population, 18,643 were initially transported to non-MTCs. 4305 (23\%) were then transferred to MTCs within 24 hours. The estimated crude mortality was significantly higher among patients who were transferred $(9.2 \%$ vs $7.5 \%, P=0.0005)$. The adjusted 30 -day cumulative death risk was consistently higher in patient treated at non-MTCs compared to patients those transferred to MTCs.

- The restricted analysis for trauma patients with an ISS >I5 marginally strengthened the protective effect of treatment at MTCs (the results were not shown).

- The propensity-adjusted survival analysis showed that transferring patients to MTCs was associated with significantly lower 30-day mortality for patients aged <65 years (HR [95\% Cl], 0.36 [0.27-0.49]) and also for patients aged $\geq 65$ years (HR [95\% Cl], 0.55 [0.48-0.64]) (After the adjustment for the propensity to be transferred, ISS, presence of a serious head injury, and presence of a penetrating injury).

*NOTE: The study did not track deaths after hospital discharge. So, patients who were discharged to intermediate care and died within 30 days were not included.

\begin{tabular}{|l|l|l|l|}
\hline $\begin{array}{l}\text { Pracht } \\
\text { et al, } \\
(201 \mathrm{I})^{67}\end{array}$ & $\begin{array}{l}\text { Ninth Revision, Clinical Modification } \\
\text { ICD-9CM codes, designated for hospitalization as emergent, } \\
\text { and had at least one injury associated with a severe risk of } \\
\text { mortality (International Classification of Diseases Injury } \\
\text { Severity Scale [ICISS], <0.85). }\end{array}$ & $\mathbf{2 8 , 9 8 8}$ & $\begin{array}{l}\text { Survival of patients admitted and } \\
\text { discharged from a designated trauma } \\
\text { centre. }\end{array}$ \\
\hline
\end{tabular}

\section{- Findings:}

- The rates of MTC treatment decreased with age as $50 \%$ of patients aged 65 to 74 years were treated at MTCs compared to $36 \%$ among patients aged 75 years to 84 years and $27 \%$ among patients aged $\geq 85$ years.

- The overall ICISS mean for all older trauma patients was 0.70 ; ranging from 0.66 (more severe) to 0.73 (less severe) in the age groups $65-74$ years and $\geq 85$ years, respectively.

- The ICISS mean in the MTC was significantly lower (0.624) compared to non-MTCs (0.744) which indicated greater severity of patients treated at MTCs.

- A greater variability was also reported in the severity level of patients treated in MTCs (SD, 0.23) compared with 0.14 .

- The results of this study showed that patients treated at MTCs were more severely injured (for example, $<1 \%$ of patients treated at non-MTCs had an ICISS $<0.10$ compared to $4.59 \%$ for all older trauma patients).

- The treatment of older trauma patients at MTCs is associated with a significant positive change in the probability of survival (marginal effect of $3.9 \%$ at the $5 \%$ level)

- However, when patients were stratified by age, the effect of MTC access on the probability of survival at the $5 \%$ level was not statistically significant for those who aged $\geq 85$ years (marginal effect of $3.6 \%$ ) compared to patients aged 65 to 74 years (marginal effect of $7 \%$ ) and patients aged 75 to 84 years (marginal effect of $4 \%$ ).

*NOTE: The study did not adjust for mechanism of injury, anatomical injury and physiological factors. The study also excluded transferred patients.

\begin{tabular}{l|l|l|l|}
$\begin{array}{l}\text { Mackenzie } \\
\text { et al, } \\
(2006)^{68}\end{array}$ & $\begin{array}{l}\text { I8-84 years trauma patients who arrived alive at } \\
\text { a participating hospital and had moderate to severe } \\
\text { trauma (at least one injury with an Abbreviated Injury } \\
\text { Scale (AIS) of at least 3). }\end{array}$ & $\begin{array}{l}15,009 \\
(4331 \text { aged } \\
\geq 55 \text { years) }\end{array}$ & $\begin{array}{l}\text { Death at hospital and 30, 90, and 365 } \\
\text { days after injury. }\end{array}$ \\
\hline
\end{tabular}

(Continued) 
Table 3 (Continued).

\section{- Findings:}

- Although older trauma patients aged $\geq 55$ years who had access to MTCs experienced decreased risk of death than those treated at non-MTCs (Relative Risk [RR] ranged from 0.88 to 0.94 ), the differences were not large when compared to those among younger adults (RR ranged from $0.6 \mathrm{I}$ to 0.68 ) and the RRs of death were not significantly different from 1.0 .

- The main limitation of this study, which was also mentioned by the authors, was the inclusion of small number of older adults with severe injuries in the analysis which resulted in wide confidence intervals for this cohort.

- The results of this study for older trauma patients ( $\geq 55$ years) who were treated at MTCs vs non-MTCs showed the following:

- In-hospital death: $12.3 \%$ vs $13.1 \%$ (RR [95\% Cl], 0.94 [0.56-I.6I]).

- Death within 30 Days after Injury: $12.4 \%$ vs $13.8 \%$ (RR [95\% Cl], 0.90 [0.56-I.44]).

- Death within 90 Days after Injury: $15.6 \%$ vs 17.8 (RR [95\% Cl], 0.88 [0.60-I.27]).

- Death within 365 Days after Injury: $20.7 \%$ vs $22.5 \%$ (RR [95\% Cl], 0.92 [0.67-1.28]).

- These results were compared to the results of younger adults aged $<55$ years old who were treated at MTCs vs non-MTCs which showed the following: - In-hospital death: $5.9 \%$ vs $9.0 \%$ (RR [95\% Cl], $0.66[0.48-0.89]$ ).

- Death within 30 Days after Injury: $5.9 \%$ vs $8.7 \%$ (RR [95\% Cl], 0.68 [0.48-0.95]).

- Death within 90 Days after Injury: 6.3\% vs $9.2 \%$ (RR [95\% Cl], 0.68 [0.50-0.94]).

- Death within 365 Days after Injury: $6.6 \%$ vs $10.8 \%$ (RR [95\% Cl], 0.61 [0.46-0.8I]).

"NOTE: The study included small number of older adults with severe injuries in the analysis which resulted in wide confidence intervals for this cohort.

\begin{tabular}{|c|c|c|c|c|}
\hline $\begin{array}{l}\text { Scheetz } \\
(2005)^{69}\end{array}$ & $\begin{array}{l}\geq 65 \text { years trauma patients who were admitted to an acute } \\
\text { care hospital (MTC or non-MTC) for the treatment of } \\
\text { motor vehicle trauma (ISS mean [SD], } 8.76[7.49] \text { ). }\end{array}$ & 1418 & $\begin{array}{l}\text { Survival, length of stay, and discharge } \\
\text { position to home. }\end{array}$ & 2000. \\
\hline
\end{tabular}

- Findings:

- The treatment at non-MTCs was associated with more than 4-fold increase in the likelihood of survival after adjusting for age and ISS (OR [95\% CI], 4.07 [2.39-6.94], $P<0.001)$.

- The admission to MTCs was associated with increased length of stay than non-MTCs by slightly more than 2.5 days $(\beta=2.64$, $P<0.00 \mathrm{I})$

- Of admitted patients to MTCs, $43.5 \%$ were discharged to home compared to $56.5 \%$ of the admitted patients to non-MTCs. The level of care was not related to discharge disposition to home (OR [95\% Cl], I.22 [0.95-I.56]) while younger age (OR [95\% Cl], 0.96 [0.95-0.98]), lower injury severity (OR [95\% Cl], 0.93 [0.92-0.95]), and shorter length of stay (OR [95\% Cl], 0.9l [0.89-0.93]) explained discharge disposition to home (P <0.00I).

*NOTE: This study adjusted for age and ISS, However, it was limited by potential residual confounding resulting from not adjusting for potential confounders such as physiological factors, comorbidities, and prehospital care.

\begin{tabular}{|l|l|l|l|}
\hline $\begin{array}{l}\text { Meldon } \\
\text { et al, } \\
(2002)^{66}\end{array}$ & $\begin{array}{l}>80 \text { years old trauma patients who were transported to } \\
\text { AC hospitals or MTCs }\end{array}$ & 455 & $\begin{array}{l}\text { Mortality outcomes between } \\
\text { patients treated at MTCs and } \\
\text { a similar cohort treated at AC } \\
\text { hospitals. }\end{array}$ \\
\hline
\end{tabular}

- Findings:

- The overall mortality for older trauma patients aged $>80$ years was $9.9 \%$ ( $n, 45 / 455)$.

- Patients treated at level I TCs had significantly higher ISS (median [IQR], 13 [4-25]) and more severe head injuries based on lower Glasgow Coma Scale (GCS) (median [IQR], I5 [3-I5]) compared to patients treated at level II TCs (ISS median [IQR], 5 [4-9]) and (GCS median [IQR], I5 [I5-I5]) and also patients treated at AC hospitals (ISS median [IQR], 4 [4-9]) and (GCS median [IQR], I5 [I4-I5]) $(P<0.00 I)$.

- This obviously resulted in higher mortality rates at level I TCs compared to level II TCs and AC hospitals as:

- 9 of $38(24 \%)$ patients treated at level I TC died $(\mathrm{P}<0.00 \mathrm{I})$.

- 10 of 191 (5.2\%) patients treated at level II TC died.

- 22 of 222 (9.9\%) patients treated at AC hospitals died.

- Lower mortality rates at level II TCs (5.2\%) were reported compared to AC hospitals (9.9\%) despite similar patients age, ISS, and GCS.

- The majority of deaths occurred in patients who had an ISS of 21 to 45 (n [\%], 20/4I [49\%]).

- The survival rate of older trauma patients who had a high ISS $(2 \mathrm{I}-45)$ was statistically significant between TCs and AC hospitals $(56 \%$ vs $8 \%$ survival, $\mathrm{P}<0.0 \mathrm{I})$. *NOTE: The study did not adjust for potential confounders such as mechanism of injury, comorbidities, shock, and other factors.

\begin{tabular}{|l|l|l|l|}
\hline $\begin{array}{l}\text { Smith et al, } \\
(1990)^{70}\end{array}$ & $\begin{array}{l}\text { All trauma patients (pediatrics, adults, and older adults) } \\
\text { who had femoral shaft fracture with operation (the group } \\
\text { of older adults was identified as those aged }>55 \text { years) and } \\
\text { treated at MTCs or non-MTCs. }\end{array}$ & $\begin{array}{l}1332(447 \\
\text { older } \\
\text { trauma } \\
\text { patients). }\end{array}$ & $\begin{array}{l}\text { Complications and death during } \\
\text { hospitalization. }\end{array}$ \\
$\begin{array}{l}\text { I985 in western } \\
\text { Pennsylvania and } \\
1986-1987 \text { in the state of } \\
\text { Maryland. }\end{array}$
\end{tabular}

(Continued) 
Table 3 (Continued).

\section{- Findings:}

- The treatment of older trauma patients (age $>55$ ) with solitary femoral fracture at MTCs was associated with lower complication rates than at non-MTCs ( $35 \%$ vs $46 \%$, respectively) and also for those with femoral fracture and other significant injuries (multiple trauma) $(33 \%$ vs $50 \%$, respectively).

- Of all I332 trauma patients, only 22 died during hospitalization (mortality rate, I.6\%). Non-MTCs had higher mortality rate (2.2\%) compared to almost $1 \%$ at MTCs.

- Of the 16 trauma patients who died in non-MTCs, 14 (88\%) had solitary femoral fractures and were aged $>70$ years.

- For the six patients who died in MTCs, four $(67 \%)$ had multiple trauma compared to non-MTCs $(P<0.05)$. Four $(67 \%)$ of them were aged less than 30 and only two $(33 \%)$ were aged $>55$ years.

- Older trauma patients who died during hospitalization had significantly prolonged LOS ( $>23$ days).

"NOTE: The study did not adjust for potential confounders such as comorbidities and severity of concomitant injuries. The study focused on a single pattern of injury (femoral fracture) which limited the generalizability of its results.

populations in different trauma systems, and assessed different outcome measures. Furthermore, some of these studies did not adjust for some important confounders such as physiological factors, comorbidities, and mechanism of injury, ${ }^{66,67,69,70}$ included small number of patients, ${ }^{68}$ excluded transfers, ${ }^{67}$ focused on single pattern of injury, ${ }^{70}$ and did not track deaths post hospital discharge within a defined period ${ }^{65}$ - all of which make comparisons difficult.

\section{Factors Affecting Appropriate Triage Decisions}

There are several unique factors that could adversely affect accurate prehospital trauma triage decisions for older patients. Some of which could directly affect meeting the thresholds of the existing triage criteria for direct transportation to an MTC including anatomical and physiological changes with age, comorbidities, and medication use. ${ }^{71}$ The efforts in recent research tried to overcome these challenges by developing geriatric-specific trauma triage criteria that are accurate enough to capture severely injured older patients. $^{71}$ However, no geriatric-specific trauma triage criteria have achieved acceptable sensitivity and/or specificity ${ }^{71}$ and some were not applied to all older trauma patients. ${ }^{8}$

Despite these factors, there are other important factors that are not related to triage criteria and could significantly affect prehospital trauma triage decisions for older patients. Previous studies have consistently shown decreased rates of destination compliance among injured patients with increasing age. ${ }^{5,12,62}$ For instance, a study from Australia showed that nearly $67 \%$ of the older trauma patients who met the triage criteria were transported to MTCs in contrast to almost $88 \%$ of the injured younger patients. ${ }^{5}$ This finding is consistent with other studies from the USA even when a specific triage tool for older adults was developed. ${ }^{4,14,62,63}$ In this regard, there is limited evidence that factors other than the triage criteria have been assessed in relation to their effect on prehospital triage decisions for older trauma patients (Table 4). No study has assessed the impact of such factors on outcomes. These initial findings showed that such factors could impact prehospital triage decisions for these patients and may, consequently, affect their outcomes.

\section{The Future}

- There is a paucity of information, worldwide, on the use of frailty assessment tools by paramedics and trauma outcomes in older people. Therefore, further efforts in future research are required to assess the feasibility and validity of frailty assessment for use in the prehospital environment.

- More studies are also required to assess the benefits of access to MTCs for older trauma patients.

- Appropriate patient- and clinician-reported, shortterm and long-term outcome measures would also need to be determined for older trauma patients.

- It seems that there are other factors such as distance to MTCs, patient or relative choice, training, unfamiliarity with protocols, and possible ageism that affect prehospital triage of older trauma patients which require further investigation and assessment.

- More focus is also needed to ensure that EMS personnel have adequate education and training to assess and treat older trauma patients and be more familiar with their protocols.

- Overall, future research in this field could significantly improve prehospital triage decisions and the transition of care from prehospital to in-hospital 
Table 4 Assessment of Other Factors Not Related to Prehospital Trauma Triage Criteria

\begin{tabular}{|c|c|c|}
\hline Study & Measured Factors & Findings \\
\hline $\begin{array}{l}\text { Garwe et al, } \\
(2017)^{7}\end{array}$ & Distance to MTCs. & $\begin{array}{l}\text { - Older trauma patients were slightly injured in regions slightly away from MTCs com- } \\
\text { - The study showed that even when older persons were injured in places close to MTCs, } \\
\text { they were less likely to be transported to these centres. }\end{array}$ \\
\hline $\begin{array}{l}\text { Newgard } \\
\text { et al, }(2016)^{13}\end{array}$ & Patient or Relative Choice. & $\begin{array}{l}\text { - }>72 \% \text { of hospital selections in the prehospital phase were made by patient or relative choice. } \\
\text { - It we study explored the role of patient or relative choice and found inconsistent results. } \\
\text { due to its subjectivity and the variations between the patients. }\end{array}$ \\
\hline $\begin{array}{l}\text { Chang et al, } \\
(2008)^{4}\end{array}$ & $\begin{array}{l}\text { Training, Unfamiliarity with } \\
\text { protocols, and Possible Ageism. }\end{array}$ & $\begin{array}{l}\text { - Surveys of EMS personnel looking into the reasons of destination non-compliance for positively } \\
\text { triaged older trauma patients showed that insufficient training to manage older trauma patients } \\
\text { could be the major contributor for this issue ( } 20 \%) \text { followed by unfamiliarity with protocols } \\
\text { (10\%) ageism (such as feeling older people are not worth the extra expenditure [5\%] and poor } \\
\text { prognoses [2\%]), and feeling unwelcomed when bringing patients to an MTC (2\%) respectively. }\end{array}$ \\
\hline
\end{tabular}

setting which could, consequently, reduce patients' complications and improve their quality of life and healthcare use and experience.

\section{Conclusion}

Prehospital care of older trauma patients represents a major part of the EMS service. This includes accurate identification and triage of this population followed by appropriate transportation to a designated facility. Prehospital triage criteria were found to be inaccurate in identifying high-risk older trauma patients. Applying other assessment tools, such as frailty identification, could be helpful. Furthermore, determining the appropriate outcome measures for older trauma patients and the benefits that they can get from their access to MTCs could improve triage and appropriate prehospital transportation which, consequently, could be positively reflected on their outcomes. Moreover, investigating factors other than triage criteria that could impact prehospital destination compliance will enhance highquality prehospital care for this population.

\section{Abbreviations}

USA, United States of America; TCs, Trauma Centers; AC, Acute Care; MTC, Major Trauma Centers; UK, United Kingdom; CFS, Clinical Frailty Scale; EMS, Emergency Medical Service; CP-CGA, Care Partner - Comprehensive Geriatric Assessment; CP-FI-CGA, Care Partner-derived Frailty Index based up on Comprehensive Geriatric Assessment; EFS, Edmonton Frail Scale; GFI, Groningen Frailty Index; GAC, Geriatric Ambulatory Care; HR, Hazard
Ratio; CI, Confidence Interval; ED, Emergency Department; PERIL, Paramedic assessing Elders at Risk of Independence Loss; OR, Odds Ratio; AUC, Area Under the Curve; ISAR, Identifying Seniors at Risk; CCDS, Computerized Clinical Decision Support; CROM, Clinician Reported Outcome Measure; PROMs, Patient Reported Outcome Measures; LOS, Length of Stay; ISS, Injury Severity Score; SF-36, 36item Short Form survey; ICU, Intensive Care Unit; SD, Standard Deviation; ADL, Activities of Daily Living; ISADL, Independency Scale of Activities of Daily Living; SFS, Short Functional Status questionnaire; CCI, Charlson Comorbidity Index; GOS, Glasgow Outcome Scale; IQR, Interquartile Range; ICISS, International Classification of Diseases Injury Severity Scale; ICD-9CM, International Classification of Diseases, Ninth Revision, Clinical Modification; AIS, Abbreviated Injury Scale; RR, Relative Risk; GCS, Glasgow Coma Scale.

\section{Ethics Approval and Informed Consent}

This article does not contain any studies with human participants or animals performed by any of the authors.

\section{Author Contributions}

All authors made a significant contribution to the work reported, whether that is in the conception, study design, execution, literature review, or in all these areas; took part in drafting, revising or critically reviewing the article; gave final approval of the version to be published; have agreed on the journal to which the article has been submitted; and agree to be accountable for all aspects of the work. 


\section{Funding}

AA is funded by King Saud bin Abdulaziz University for Health Sciences, Riyadh, Saudi Arabia. The role of this funding is to publish the study as open access.

\section{Disclosure}

Professor Simon Conroy reports the receipt of NIHR grant funding to study emergency care. The authors declare that they have no other competing interests.

\section{References}

1. United Nations, Department of Economic and Social Affairs, Population Division. World Population Ageing 2015 (ST/ESA/Sera/ 390). New York: United Nations; 2015.

2. Trauma Trunkey D. Accidental and intentional injuries account for more years of life lost in the U.S. than cancer and heart disease. Among the prescribed remedies are improved preventive efforts, speedier surgery and further research. Sci Am. 1983;249(2):28-35.

3. Brown E, Tohira H, Bailey P, Fatovich D, Pereira G, Finn J. Older age is associated with a reduced likelihood of ambulance transport to a trauma centre after major trauma in Perth. Emerg Med Australas. 2019;31(5):763-771. doi:10.1111/1742-6723.13244

4. Chang DC, Bass RR, Cornwell EE, MacKenzie EJ. Undertriage of elderly trauma patients to state-designated trauma centers. Arch Surg. 2008;143(8):776-781. doi:10.1001/archsurg.143.8.776

5. Cox S, Morrison C, Cameron P, Smith K. Advancing age and trauma: triage destination compliance and mortality in Victoria, Australia. Injury. 2014;45(9):1312-1319. doi:10.1016/j.injury.2014.02.028

6. Davis JS, Allan BJ, Sobowale O, Ivascu F, Orion K, Schulman CI. Evaluation of a new elderly trauma triage algorithm. South Med J. 2012;105(9):447-451. doi:10.1097/SMJ.0b013e318261f6f4

7. Garwe T, Stewart K, Stoner J, et al. Out-of-hospital and inter-hospital under-triage to designated tertiary trauma centers among injured older adults: a 10-year statewide geospatial-adjusted analysis. Prehosp Emerg Care. 2017;21(6):734-743. doi:10.1080/10903127.2017.1332123

8. Ichwan B, Darbha S, Shah MN, et al. Geriatric-specific triage criteria are more sensitive than standard adult criteria in identifying need for trauma center care in injured older adults. Ann Emerg Med. 2015;65 (1):92-100. doi:10.1016/j.annemergmed.2014.04.019

9. Kodadek LM, Selvarajah S, Velopulos CG, Haut ER, Haider AH. Undertriage of older trauma patients: is this a national phenomenon? J Surg Res. 2015;199(1):220-229. doi:10.1016/j.jss.2015.05.017

10. Lehmann R, Beekley A, Casey L, Salim A, Martin M. The impact of advanced age on trauma triage decisions and outcomes: a statewide analysis. Am J Surg. 2009;197(5):571-575. doi:10.1016/j.amjsurg. 2008.12.037

11. Meyers MH, Wei TL, Cyr JM, et al. The triage of older adults with physiologic markers of serious injury using a state-wide prehospital plan. Prehosp Disaster Med. 2019;34(5):497-505. doi:10.1017/ S1049023X19004825

12. Nakamura Y, Daya M, Bulger EM, et al. Evaluating age in the field triage of injured persons. Ann Emerg Med. 2012;60(3):335-345. doi:10.1016/j.annemergmed.2012.04.006

13. Newgard CD, Holmes JF, Haukoos JS, et al. Improving early identification of the high-risk elderly trauma patient by emergency medical services. Injury. 2016;47(1):19-25. doi:10.1016/j.injury.2015.09.010

14. Newgard CD, Lin A, Eckstrom E, et al. Comorbidities, anticoagulants, and geriatric-specific physiology for the field triage of injured older adults. J Trauma Acute Care Surg. 2019;86(5):829-837. doi:10.1097/TA.0000000000002195
15. Staudenmayer KL, Hsia RY, Mann NC, Spain DA, Newgard CD. Triage of elderly trauma patients: a population-based perspective. J Am Coll Surg. 2013;217(4):569-576. doi:10.1016/j.jamcollsurg.2013.06.017

16. Rotondo M, Cribari C, Smith R; American College of Surgeons Committee on Trauma. Resources for Optimal Care of the Injured Patient. Vol. 6. Chicago, USA: American College of Surgeons; 2014.

17. Brown JB, Gestring ML, Forsythe RM, et al. Systolic blood pressure criteria in the National Trauma Triage Protocol for geriatric trauma: 110 is the new 90. J Trauma Acute Care Surg. 2015;78(2):352-359. doi:10.1097/TA.0000000000000523

18. Doherty TJ. Invited review: aging and sarcopenia. J Appl Physiol. 2003;95(4):1717-1727. doi:10.1152/japplphysiol.00347.2003

19. Ferrara N, Komici K, Corbi G, et al. $\beta$-adrenergic receptor responsiveness in aging heart and clinical implications. Front Physiol. 2014;4:396. doi:10.3389/fphys.2013.00396

20. Gerstenblith G, Frederiksen J, Yin F, Fortuin NJ, Lakatta EG, Weisfeldt ML. Echocardiographic assessment of a normal adult aging population. Circulation. 1977;56(2):273-278. doi:10.1161/01. CIR.56.2.273

21. Hedman AM, van Haren NE, Schnack HG, Kahn RS, Hulshoff Pol HE. Human brain changes across the life span: a review of 56 longitudinal magnetic resonance imaging studies. Hum Brain Mapp. 2012;33(8):1987-2002. doi:10.1002/hbm.21334

22. Janssen I, Heymsfield SB, Ross R. Low relative skeletal muscle mass (sarcopenia) in older persons is associated with functional impairment and physical disability. J Am Geriatr Soc. 2002;50(5):889-896. doi:10.1046/j.1532-5415.2002.50216.x

23. Sharma G, Goodwin J. Effect of aging on respiratory system physiology and immunology. Clin Interv Aging. 2006;1(3):253-260. doi:10. 2147/ciia.2006.1.3.253

24. Xu X, Wang B, Ren C, et al. Age-related impairment of vascular structure and functions. Aging Dis. 2017;8(5):590-610. doi:10.14336/ AD.2017.0430

25. Rickard F, Ibitoye S, Deakin H, et al. The Clinical Frailty Scale predicts adverse outcome in older people admitted to a UK major trauma centre. Age Ageing. 2020;2020:1-7.

26. O’Caoimh R, Costello M, Small C, et al. Comparison of frailty screening instruments in the emergency department. Int J Environ Res Public Health. 2019;16(19):3626. doi:10.3390/ijerph16193626

27. van Rein EA, van der Sluijs R, Raaijmakers AM, Leenen LP, van Heijl M. Compliance to prehospital trauma triage protocols worldwide: a systematic review. Injury. 2018;49(8):1373-1380. doi:10.10 16/j.injury.2018.07.001

28. Alshibani A, Banerjee J, Lecky F, et al. A consensus building exercise to determine research priorities for silver trauma. BMC Emerg Med. 2020;20(1):1-8. doi:10.1186/s12873-020-00357-4

29. Trauma Audit and Research Network (TARN). Major Trauma in Older People. Salford/United Kingdom; April 04, 2017:1.

30. Joosten E, Demuynck M, Detroyer E, Milisen K. Prevalence of frailty and its ability to predict in hospital delirium, falls, and 6-month mortality in hospitalized older patients. BMC Geriatr. 2014;14(1):1. doi:10.1186/1471-2318-14-1

31. Pecheva M, Phillips M, Hull P, O'Leary RCA, Queally J. The impact of frailty in major trauma in older patients. Injury. 2020;51 (7):1536-1542. doi:10.1016/j.injury.2020.04.045

32. Curtis E, Romanowski K, Sen S, Hill A, Cocanour C. Frailty score on admission predicts mortality and discharge disposition in elderly trauma patients over the age of 65 y. J Surg Res. 2018;230:13-19. doi:10.1016/j.jss.2018.04.017

33. Joseph B, Pandit V, Zangbar B, et al. Superiority of frailty over age in predicting outcomes among geriatric trauma patients: a prospective analysis. JAMA Surg. 2014;149(8):766-772. doi:10.1001/jamasurg. 2014.296

34. Sadarangani T, Squires A. Frailty as a predictive factor in geriatric trauma patient outcomes. J Clin Outcomes Manag. 2014;21 (9):396-397. 
35. Goldstein J, Hubbard RE, Moorhouse P, Andrew MK, Mitnitski A, Rockwood $\mathrm{K}$. The validation of a care partner-derived frailty index based upon comprehensive geriatric assessment (CP-FI-CGA) in emergency medical services and geriatric ambulatory care. Age Ageing. 2015;44(2):327-330. doi:10.1093/ageing/afu161

36. Goldstein J, Travers A, Hubbard R, Moorhouse P, Andrew MK, Rockwood K. Assessment of older adults by emergency medical services: methodology and feasibility of a care partner Comprehensive Geriatric Assessment (CP-CGA). CJEM. 2014;16(5):370-383.

37. Harris W, Lucas PV, Eyles H, Parker L. Paramedic assessment of frailty: an exploratory study of perceptions of frailty assessment tools. Ir J Paramed. 2018;3(1):1-10. doi:10.32378/ijp.v3i1.80

38. Lee JS, Verbeek PR, Schull MJ, et al. Paramedics assessing Elders at Risk for Independence Loss (PERIL): derivation, reliability and comparative effectiveness of a clinical prediction rule. CJEM. 2016;18(2):121-132. doi:10.1017/cem.2016.14

39. Snooks HA, Carter B, Dale J, et al. Support and Assessment for Fall Emergency Referrals (SAFER 1): cluster randomised trial of computerised clinical decision support for paramedics. PLoS One. 2014;9 (9):e106436. doi:10.1371/journal.pone.0106436

40. Smith PG, Morrow RH, Ross DA. Field Trials of Health Interventions: A Toolbox. OUP Oxford; 2015.

41. Moran CG, Lecky F, Bouamra O, et al. Changing the systemmajor trauma patients and their outcomes in the NHS (England) 2008-17. EClinicalMedicine. 2018;2:13-21. doi:10.1016/j. eclinm.2018.07.001

42. Akpan A, Roberts C, Bandeen-Roche K, et al. Standard set of health outcome measures for older persons. BMC Geriatr. 2018;18(1):36. doi:10.1186/s12877-017-0701-3

43. Gabbe BJ, Williamson OD, Cameron PA, Dowrick AS. Choosing outcome assessment instruments for trauma registries. Acad Emerg Med. 2005;12(8):751-758. doi:10.1197/j.aem.2005.03.527

44. Hoffman K, Cole E, Playford ED, Grill E, Soberg HL, Brohi K. Health outcome after major trauma: what are we measuring? PLoS One. 2014;9(7):e103082. doi:10.1371/journal.pone.0103082

45. Rosenberg GM, Stave C, Spain DA, Weiser TG. Patient-reported outcomes in trauma: a scoping study of published research. Trauma Surg Acute Care Open. 2018;3(1):e00202. doi:10.1136/tsaco-2018000202

46. Sleat GK, Ardolino AM, Willett KM. Outcome measures in major trauma care: a review of current international trauma registry practice. Emerg Med J. 2011;28(12):1008-1012. doi:10.1136/ emermed-2011-200326

47. Ardolino A, Sleat G, Willett K. Outcome measurements in major trauma-results of a consensus meeting. Injury. 2012;43 (10):1662-1666. doi:10.1016/j.injury.2012.05.008

48. Koizia L, Kings R, Koizia A, et al. Major trauma in the elderly: frailty decline and patient experience after injury. Trauma. 2019;21 (1):21-26. doi:10.1177/1460408618783221

49. Inaba K, Goecke M, Sharkey P, Brenneman F. Long-term outcomes after injury in the elderly. J Trauma Acute Care Surg. 2003;54 (3):486-491. doi:10.1097/01.TA.0000051588.05542.D6

50. DeMaria EJ, Kenney PR, Merriam MA, Casanova LA, Gann DS. Aggressive trauma care benefits the elderly. $J$ Trauma Acute Care Surg. 1987;27(11):1200-1206. doi:10.1097/00005373-198711000-00002

51. McKevitt EC, Calvert E, Ng A, et al. Geriatric trauma: resource use and patient outcomes. Can J Surg. 2003;46(3):211-215.

52. Ferrera PC, Bartfield JM, D'Andrea CC. Geriatric trauma: outcomes of elderly patients discharged from the ED. Am J Emerg Med. 1999;17(7):629-632. doi:10.1016/S0735-6757(99)90146-8

53. Carrillo EH, Richardson JD, Malias MA, Cryer H, Miller FB. Long term outcome of blunt trauma care in the elderly. Surg Gynecol Obstet. 1993;176(6):559-564.
54. Zietlow SP, Capizzi PJ, Bannon MP, Farnell MB. Multisystem geriatric trauma. J Trauma Acute Care Surg. 1994;37(6):985-988. doi:10.1097/00005373-199412000-00020

55. van der Sluis CK, Klasen H, Eisma W, Ten Duis H. Major trauma in young and old: what is the difference? J Trauma Acute Care Surg. 1996;40(1):78-82. doi:10.1097/00005373-199601000-00015

56. Oreskovich MR, Howard JD, Copass MK, Carrico CJ. Geriatric trauma: injury patterns and outcome. $J$ Trauma. 1984;24(7):5 65-572. doi:10.1097/00005373-198407000-00003

57. Battistella FD, Din AM, Perez L. Trauma patients 75 years and older: long-term follow-up results justify aggressive management. $J$ Trauma. 1998;44(4):618-624. doi:10.1097/00005373-199804000-00010

58. Day RJ, Vinen J, Hewitt-Falls E. Major trauma outcomes in the elderly. Med J Aust. 1994;160(11):675-678.

59. Kelley-Quon L, Min L, Morley E, Hiatt JR, Cryer H, Tillou A. Functional status after injury: a longitudinal study of geriatric trauma. Am Surg. 2010;76(10):1055-1058. doi:10.1177/000313481007601006

60. Alavi NM, Safa A, Abedzadeh-Kalahroudi M. Dependency in activities of daily living following limb trauma in elderly referred to shahid beheshti hospital, kashan-Iran in 2013. Arch Trauma Res. 2014;3(3):e20608.

61. van Aalst J, Morris JJ, Yates H, Miller R, Bass S. Severely injured geriatric patients return to independent living: a study of factors influencing function and independence. $J$ Trauma. 1991;31 (8):1096-1101. doi:10.1097/00005373-199131080-00008

62. Amoako J, Evans S, Brown NV, Khaliqdina S, Caterino JM. Identifying predictors of undertriage in injured older adults after implementation of statewide geriatric trauma triage criteria. Acad Emerg Med. 2019;26(6):648-656. doi:10.1111/acem.13695

63. Caterino JM, Brown NV, Hamilton MW, et al. Effect of geriatric-specific trauma triage criteria on outcomes in injured older adults: a statewide retrospective cohort study. $J$ Am Geriatr Soc. 2016;64(10):1944-1951. doi:10.1111/jgs.14376

64. Phillips S, Rond PC, Kelly SM, Swartz PD. The failure of triage criteria to identify geriatric patients with trauma: results from the Florida Trauma Triage Study. J Trauma Acute Care Surg. 1996;40 (2):278-283. doi:10.1097/00005373-199602000-00018

65. Garwe T, Stewart KE, Newgard CD, et al. Survival benefit of treatment at or transfer to a tertiary trauma center among injured older adults. Prehosp Emerg Care. 2020;24(2):245-256. doi:10.1080/109 03127.2019.1632997

66. Meldon SW, Reilly M, Drew BL, Mancuso C, Fallon JW Jr. Trauma in the very elderly: a community-based study of outcomes at trauma and nontrauma centers. J Trauma Acute Care Surg. 2002;52(1): 79-84. doi:10.1097/00005373-200201000-00014

67. Pracht EE, Langland-Orban B, Flint L. Survival advantage for elderly trauma patients treated in a designated trauma center. J Trauma Acute Care Surg. 2011;71(1):69-77. doi:10.1097/TA.0b013e31820e82b7

68. MacKenzie EJ, Rivara FP, Jurkovich GJ, et al. A national evaluation of the effect of trauma-center care on mortality. $N$ Engl $J$ Med. 2006;354(4):366-378. doi:10.1056/NEJMsa052049

69. Scheetz LJ. Differences in survival, length of stay, and discharge disposition of older trauma patients admitted to trauma centers and nontrauma center hospitals. $J$ Nurs Scholarsh. 2005;37(4):361-366. doi:10.1111/j.1547-5069.2005.00062.x

70. Smith JS, Martin LF, Young WW, Macioce DP. Do trauma centers improve outcome over non-trauma centers: the evaluation of regional trauma care using discharge abstract data and patient management categories. J Trauma. 1990;30(12):1533-1538. doi:10.1097/00005 373-199012000-00017

71. Alshibani A, Singler B, Conroy S. Towards improving prehospital triage for older trauma patients. Z Gerontol Geriatr. 2021. doi:10. 1007/s00391-021-01844-4 
Open Access Emergency Medicine

\section{Publish your work in this journal}

The Open Access Emergency Medicine is an international, peerreviewed, open access journal publishing original research, reports, editorials, reviews and commentaries on all aspects of emergency and includes a very quick and fair peer-review system, which is al easy to use. Visit http://www.dovepress.com/testimonials.php to read real quotes from published authors. 